\title{
When least is most
}

\author{
Stephen Hancocks OBE \\ Editor-in-Chief
}

The $B D J$ Upfront section includes editorials, letters, news, book reviews and interviews. Please direct your correspondence to the News Editor,

Kate Quinlan at k.quinlan@nature.com. Press releases or articles may be edited, and should include a colour photograph if possible.

I $\mathrm{t}$ is interesting in life how various streams from diverse directions can from time to time coalesce to create a greater sense of direction. In recent weeks three strands seem to me to have suggested routes forwards in oral health.

My previous editorial on global oral health, stimulated by the UCL event to mark the publication of an oral health series in The Lancet, has brought a polite rebuke and reassurance from the authors in the form of a letter, published in this issue. ${ }^{1,2}$ They correct me in my contention that the overriding message of the series was that individual treatment was no longer the way forward. On the contrary they call for radical reform of oral healthcare systems to enable clinicians to deliver high quality and appropriate care to their patients, combined with policy changes to promote population oral health and reduce inequalities. While coming I am sure as a relief to readers it does also pose a further question of quite how the workflow of the individual clinician is to be forged in order to allow the new order of things.

Perhaps the two papers in this issue by Martignon et al. offer a way forward. ${ }^{3,4}$ CariesCare International is a charity promoting a patient-centred, risk-based approach to caries management and the main paper describes their practice guide. This includes the detailed application of the care process but also the painstaking route to its creation over nearly two decades of expert deliberation. It has been said that if one assembles three dentists in a room one will get at least four sets of opinions. It seems that gathering three cariologists produces at least half a dozen diverse views. Be that as it may, the meticulous CariesCare route is the result and is, in essence, a packaging of minimal intervention dentistry (MID) which is a philosophy that we have been supporting in the $B D J$ for some time. Indeed we are planning a further themed issue on the subject next year.
The CariesCare practice guide has been designed to be applicable to the individual patient by the individual clinician (with dental team involvement as appropriate). Utilising a 'four D' approach: Detect, Decide, Do and Determine as a logical, and familiar, method it encompasses all that we already know to be good sense and best practice. As such it may well be argued that it provides a solution to one or more of the problems posed by The Lancet series authors since it encompasses the common risk factor approach to wider health most specifically by its incorporation of sugar in dietary advice. However, more than this, the nature of it as a comprehensive process makes it 'convenient' as a concept that policy makers may stand the best chance to date of succeeding where the previous patchwork quilt of confusing offerings has failed. Some practitioners have even found ways to implement MID to a limited extent under the current UDA system of remuneration in the UK. One is tempted to suggest that if it is possible under what is regarded as such a flawed and widely discredited system as this, then it has a bright future under more enlightened circumstances.

The one further strand that I think feeds significantly into this direction of travel relates to the Minamata agreement and the phase down of the use of dental amalgam. As noted previously, European governments have been required to produce a national plan outlining steps being taken towards this goal. ${ }^{5}$

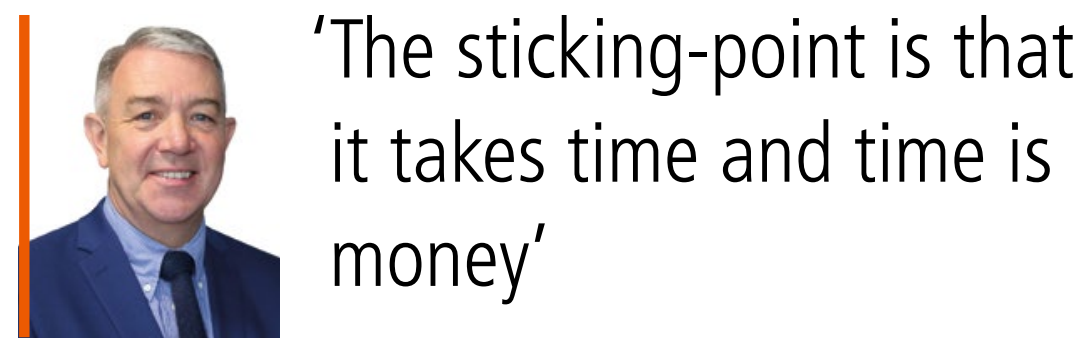

can potentially lift more easily from the shelf. This is important because it could provide a universally accepted system for future care pathways.

In the UK we have passed through the well-rehearsed sequence of widespread caries and extractions, dentures, conservation and prevention. Thus the philosophy of minimal intervention makes perfect logical and evidence-based sense to us as clinicians and as professionals in a scientific and social context. The sticking-point is that it takes time and time is money. Healthcare providers, governments and others, are therefore understandably reluctant to sanction such care plans untethered by financial constraints. A system such as CariesCare that has the potential to be managed and to some extent contained
Significantly, that from the Welsh government specifically mentions the MID approach. Perhaps, just perhaps, CariesCare as a conveniently perceived packaging of MID could lead the way not just in the UK but globally as an integrated way forward. It's persuasive.

\section{References}

1. Hancocks S. Global oral health; eggs and stones. Br Dent J 2019; 227: 173.

2. Watt $R$, Daly $B$, Mathur M, Benzian $H$, Macpherson, $L M$ D. Beyond the dental silo. Br Dent J 2019; 227: 329.

3. Martignon S, Pitts N G, Goffin G et al. CariesCare practice guide: Consensus of evidence into practice. $\mathrm{Br}$ Dent J 2019; 227: 353-362

4. Beltrán E O, Guiu L, Zarta O L, Pitts N B, Martignon S. Caries classification and management in the context of the CariesCare International (CCIMM) consensus: a clinical case study. Br Dent J 2019; 227: 363-366.

5. Hancocks S. Devolved amalgamation. Br Dent J 2019; 227: 245.

https://doi.org/ 10.1038/s41415-019-0740-6 